Final Report

\title{
UPDATE AND EXPANSION OF THE CENTER OF AUTOMOTIVE TECHNOLOGY EXCELLENCE UNDER THE GRADUATE AUTOMOTIVE TECHNOLOGY EDUCATION (GATE) PROGRAM AT THE UNIVERSITY OF TENNESSEE, KNOXVILLE
}

(Cooperative Agreement Number DE-FG26-05NT42619)

\author{
The University of Tennessee, Knoxville \\ Knoxville, Tennessee \\ Reporting Period: \\ October 1, 2005 to August 31, 2012
}

\author{
Submitted to: \\ Ms. Adrienne Riggi \\ Project Manager \\ U.S. Department of Energy \\ National Energy Technology Laboratory \\ 3610 Collins Ferry Road \\ P.O. Box 880 \\ Morgantown, WV 26507-0880 \\ Submitted by: \\ Dr. David K. Irick \\ Professor and GATE Director \\ 414 Dougherty Engineering Building \\ The University of Tennessee \\ Knoxville, TN 37996-2210
}

November 27, 2012 


\section{DISCLAIMER}

This report was prepared as an account of work sponsored by an agency of the United States Government. Neither the United States Government nor any agency thereof, nor any of their employees, makes any warranty, express or implied, or assumes any legal liability or responsibility for the accuracy, completeness, or usefulness of any information, apparatus, product, or process disclosed, or represents that its use would not infringe privately owned rights. Reference herein to any specific commercial product, process, or service by trade name, trademark, manufacturer, or otherwise does not necessarily constitute or imply its endorsement, recommendation, or favoring by the United States Government or any agency thereof. The views and opinions of authors expressed herein do not necessarily state or reflect those of the United States Government or any agency thereof. 


\section{Contents}

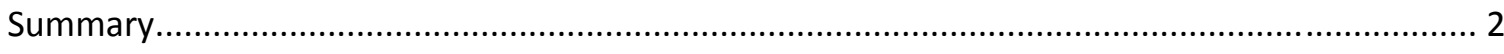

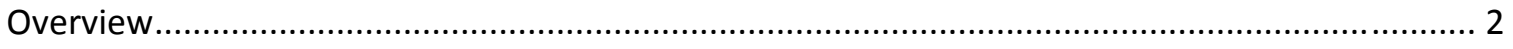

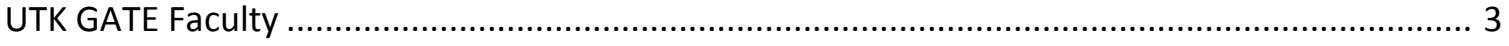

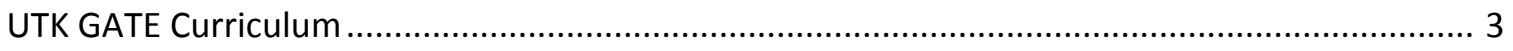

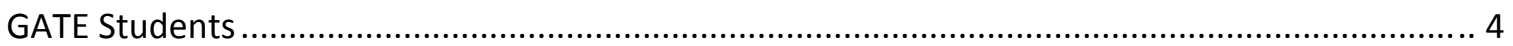

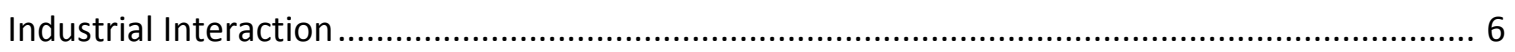

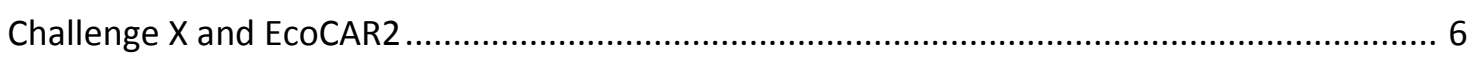

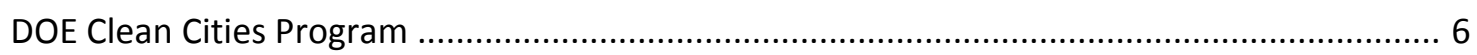

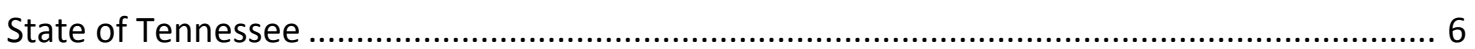

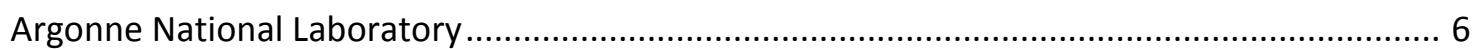

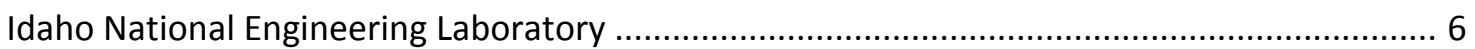

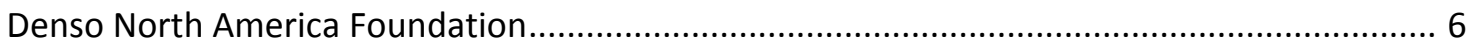

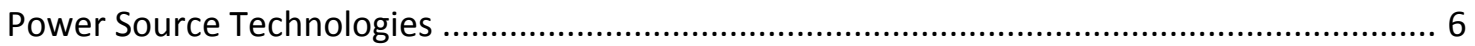

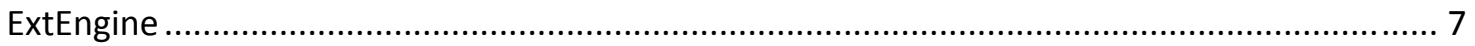

3M

NTRC

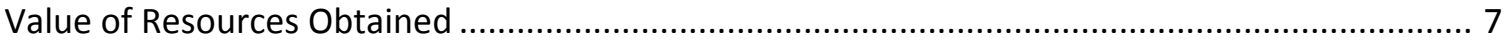

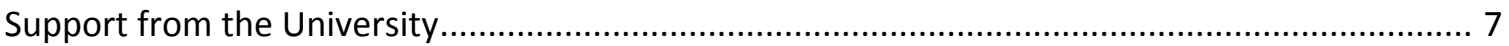

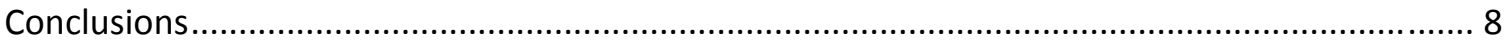




\section{Summary}

The Graduate Automotive Technology Education (GATE) Center at the University of Tennessee, Knoxville has completed its seventh year of operation under this agreement, its thirteenth year in total. During this period the Center has involved eleven GATE Fellows and three GATE Research Assistants in preparing them to contribute to advanced automotive technologies in the center's focus area: Advanced Hybrid Propulsion and Control Systems.

In addition to the impact that the Center has had on the students and faculty involved, the presence of the center has led to the acquisition of resources that probably would not have been obtained if the GATE Center had not existed. Significant industry interaction such as equipment donations, and support for GATE students has been realized. The value of the total resources brought to the university (including related research contracts) exceeds $\$ 2,000,000$.

\section{Overview}

The UTK GATE Center was originally established in 1998 with the original grant and was fortunate enough to be awarded the current grant to continue. The Center's focus area is Advanced Hybrid Propulsion and Control Systems, with a specific focus on the following areas.

- Enhancing hybrid systems based on IC engines and transitional engine technologies

- Developing optimal strategies for powertrain control and systems integration respective of fuel efficiency, emissions, energy management and dynamic performance

- Developing objective performance measures and mitigation strategies for powertrain performance issues unique to hybrid vehicles that represent barriers to customer acceptance

- Providing metrics for an objective comparison of advanced hybrid vehicles based on detailed performance measures of optimally-controlled systems

The GATE Center at UTK is housed in the College of Engineering with administrative support (accounting, purchasing, etc.) in the Mechanical, Aerospace and Biomedical Engineering Department. The Center Director, who comes from that department, is responsible for the operation of the Center in consultation with the other GATE Faculty. The Director also makes decisions (in consultation with the other GATE Faculty) regarding the allocation of Fellowships.

Close working relationships are maintained with the National Transportation Research Center (NTRC), a joint venture between UTK and Oak Ridge National Laboratory (ORNL). As discussed below, several important industrial partnerships have served to benefit the students involved in the GATE Center.

There are two classifications of UTK GATE students: GATE Fellows (those who receive GATE Fellowships) and GATE Research Assistants (those who are following the GATE curriculum, but do not have a GATE Fellowship). GATE Fellows are expected to mentor undergraduate students working on the DOE-sponsored Advanced Vehicle Technology Competition vehicles (Challenge $\mathrm{X}$ and ECOCAR2) as part of their responsibilities. 


\section{UTK GATE Faculty}

The GATE faculty represent an impressive collection of enthusiastic and qualified individuals with varied backgrounds that contribute to the mission of the UTK GATE Center.

- Bill Hamel (ME):

- David Irick, Director (ME):

- Leon Tolbert (EE):

- Wes Hines (NE):

- David Smith (ME): hybrid vehicle controls

internal combustion engines, mechanical design power electronics fuzzy logic, artificial intelligence hybrid vehicle controls, HIL simulation

\section{UTK GATE Curriculum}

Several specific courses were developed within the existing curricula of the traditional engineering disciplines, under the original GATE grant.

ME 588 (3) Introduction to Hybrid Electric Vehicles - Series, parallel, and dual configurations. Sizing and analysis of typical HEV components: motors, auxiliary power sources, on-board energy storage, and fuels. Steady-state HEV force and power modeling schemes. Powertrain design using various computer simulation tools.

ME 523 (3) Special Topics in Thermodynamics- Advanced Internal Combustion Engines. Combustion and computer modeling of internal combustion engine processes. Alternative fuels, emissions and emission controls, valve timing.

ME 642 (3) Advanced Internal Combustion Engines- This course covers several aspects of current engines supplied in on-road vehicles. The course focuses on the operation of the engine as a sub-system within the vehicle. Advanced engine designs with emphasis on those designs that offer improved emissions and fuel economy performance.

ME 689 (3) Hybrid Electric Vehicle Advanced Controls- Nonlinear modeling and control issues associated with HEV power trains: fuzzy and neural control techniques. Adaptive and optimal control schemes for vehicle performance enhancement. Review of modern automotive control hardware and software trends and practices.

EE 599 (3) Power Electronics and Drives for Hybrid Electric Vehicles- Modern power electronic devices and various electric motor configurations with emphasis on their applications in hybrid electric vehicles.

ECE 523 (3) Power Electronics and Drives- Principles, pulse-width modulation techniques, and control for three-phase power converters. Average models of three-phase converters in stationary and rotating reference frames. Small-signal models in rotating reference frame and control design. Three-phase inverter applications as motor drives. Drive system modeling and control.

ECE 525 (3) Alternative Energy Sources- Energy outlook, interconnection issues of distributed energy resources, efficiency of power production, electric energy conversion and storage. Photovoltaics, fuel cells, wind turbines, microturbines. 
ECE 615 (3) Control of Electric Machines- Models in the form of nonlinear differential equations are developed for the induction, synchronous, brushless DC and switched reluctance motors. High performance methods of control based on state space techniques are developed including field-oriented and input-output linearization control.

ECE 629 (3) Traction Drives- Operating principles of traction drives for electric and hybrid electric vehicles. Low speed constant torque control mode and high speed constant power control mode. Ideal performance of the doubly fed, separately excited dc machine and the wound rotor synchronous machine. High CPSR drives based on singly-fed machines including the induction, permanent magnet synchronous, brushless dc and switched reluctance motors. Other contemporary topics in traction drive applications.

Two new courses were developed within the existing curricula of the traditional engineering disciplines, under the current GATE grant.

ME 599 (3) Hybrid Vehicle Simulation and Controls Development- Advanced vehicle level modeling. Fundamental approaches and processes for vehicle modeling. Tools for developing complete vehicle models (MATLAB/Simulink, DOE Autonomie). Vehicle supervisory control principles for advanced powertrains.

ME 599 (3) Rapid Controls Prototyping - Fundamental in-vehicle network communications. Hardware-in-the-loop principles and applications. Real-time modeling and simulation considerations. Software-in-the-loop, component-in-the-loop development. Plant model development and adaption to HIL environments. Fault logic development and implementation. Design Failure Modes and Effects Analysis (DFMEA). Fault Tree Analysis (FTA). HIL validation/verification and fault insertion methods. Development of verification test plans.

In addition, materials for two courses were updated and expanded-ME523 Special Topics in Thermodynamics and ME642 Advanced Internal Combustion Engines.

\section{GATE Students}

Eleven students have enrolled with GATE Fellowships. Of these eleven, eight have graduated, one has completed her course work and is involved in research, and two left the university. In addition to the GATE fellows, three GATE Research Assistants have graduated. Below is a listing of GATE students.

\section{GATE Student Fellows}

John Miller completed his M.S. degree in mechanical engineering in May 2006 and is employed at Southwest Research Institute. His research involved the design of a single axle series regenerative braking system for a hybrid electric vehicle.

Shaun Hinds completed his M.S. degree in mechanical engineering in May 2007 and is employed at BorgWarner Turbo Systems. His graduate program focused on vehicle system design. 
Courtney Lindwurm began her graduate studies toward the Ph.D. degree in mechanical engineering in August 2006. Courtney decided to take a full-time position with General Motors rather than continuing her graduate studies.

Sean Peterson began his graduate studies toward the M.S. degree in mechanical engineering in June 2007. Sean's research focused on characterizing the effects of biodiesel quality on the performance of advanced aftertreatment systems. Sean decided to pursue full-time employment rather than continue his degree program.

Scott Curran completed his M.S. degree in mechanical engineering in May 2009 and is employed at Oak Ridge National Lab. Scott's research has focused on characterizing the effects of biodiesel quality on the performance of advanced aftertreatment systems.

David Smith completed his graduate studies toward the Ph.D. degree in mechanical engineering in May 2009 and is employed as Program Manager for Vehicle Systems at Oak Ridge National Lab. His research focused on evaluation of plug-in hybrid control system optimization.

Benjamin Newcomer completed his graduate studies toward the MS degree in mechanical engineering in May 2011. His research was in the area of PHEV engine control and energy management strategies.

Ryan Howell completed his M.S. degree in mechanical engineering in August 2012 and is employed at BorgWarner Turbo Systems. His research was in the area of PHEV system integration.

Mitchel Routh completed his graduate studies toward the MS degree in mechanical engineering in August 2012 and is employed at General Motors. His research was in the area of PHEV controls development.

Michael Pickelsimer completed his graduate studies toward the MS degree in electrical engineering in August 2012 and is employed at General Motors. His research was in the area of inverter design.

Yutian Liu began her graduate studies toward the PhD degree in electrical engineering in August 2009. Her research is in the area of high temperature power electronics for HEVs.

\section{GATE Research Assistants}

Balaji Ramamurthy completed his MS degree in mechanical engineering in May 2006 and is employed at Siemens. His research dealt with the design of a reverse-flow oxidation catalyst system for lean burn natural gas engines.

Chris Hamilton completed his MS degree in mechanical engineering in May 2006 and is employed at Westinghouse. His research dealt with first and second law analyses of advanced combustion modes in diesel engines.

Dean Deter completed his MS degree in mechanical engineering in May 2012 and is employed as a Post-Masters Fellow at Oak Ridge National Lab. His research was in the area of PHEV engine control and energy management strategies.

Six of the GATE Fellows participated on the UTK Challenge X program, and three of the GATE Fellows participated in EcoCAR2. 


\section{Industrial Interaction}

The UTK GATE Center has had significant support from industrial partners. These are briefly presented below.

\section{Challenge $X$ and EcoCAR2}

The UTK efforts in the DOE-sponsored Challenge $X$ and EcoCAR2 competitions were conducted as GATE Center activities with the GATE students providing leadership and mentoring to the undergraduate students. This activity, of course, involved significant support from industry (General Motors and the many other partners in these efforts). The involvement of the GATE Center not only provided support for the competition effort, but also allowed our students to become involved with hardware and software that they otherwise would not have had access to.

\section{DOE Clean Cities Program}

The UTK GATE Center has enjoyed an active collaboration with the local Clean Cities program, The East Tennessee Clean Fuels Coalition. Many of the GATE students have participate in the Coalition meetings and outreach activities.

\section{State of Tennessee}

The Tennessee Department of Environment and Conservation provide a grant for biodiesel research that partially supported two GATE Fellows and resulted in one of the Fellow's M.S. thesis.

\section{Argonne National Laboratory}

In addition to the Advanced Vehicle Technology Competitions, ANL sponsored research in PHEV controls development that resulted in the Ph.D. dissertation for one of the GATE Fellows.

Idaho National Engineering Laboratory

Idaho National Engineering Laboratory provided an ABC-150 battery simulator on loan to support GATE research activities.

\section{Denso North America Foundation}

DNFA has provided support for upgrades to the laboratory facilities amounting to $\$ 200,000$. The upgrades include emissions measurement equipment, chassis dynamometer controls upgrade and data acquisition.

Power Source Technologies

PST has sponsored research related to development of the Legacy engine. 


\section{ExtEngine}

ExtEngine provided the SCR ammonia dosing system and technical support for the UTK Challenge $X$ vehicle.

\section{$3 M$}

$3 \mathrm{M}$ provided the catalyst and technical support for the Challenge $\mathrm{X}$ vehicle's SCR system.

NTRC

Although not an industrial entity, the National Transportation Research Center has provided both equipment and student support to help the GATE Center to achieve its objectives. Nine GATE students have benefited directly from this partnership.

\section{Value of Resources Obtained}

Since the GATE Center does not act as a conduit for resources brought to the university, the GATE Center does not have an audited list of resources it "owns". It is possible, however, to list resources that were brought to the university as a result of actions taken by GATE faculty that are associated with the GATE Center's focus area and that involved GATE students and faculty. This list includes:

\begin{tabular}{|l|r|}
\hline The GATE Center (DOE) & $\$ 625,000$ \\
\hline Technical Support in Automotive Engineering (DOE via ORNL) & $\$ 15,000$ \\
\hline Evaluation of Legacy Engine & $\$ 58,000$ \\
\hline Evaluation of EconoPlug & $\$ 50,000$ \\
\hline PHEV Engine Emissions Impacts on Control Strategy (DOE via ANL) & $\$ 30,000$ \\
\hline Evaluation of Legacy Engine & $\$ 202,000$ \\
\hline UT Biodiesel Model for Sustainable Biodiesel Production (TDEC) & $\$ 99,000$ \\
\hline PHEV Engine Control and Energy Management Strategy (DOE via ORNL) & $\$ 204,000$ \\
\hline Legacy Engine Demonstration Project & $\$ 59,000$ \\
\hline Denso North America Foundation (laboratory upgrades) & $\$ 200,000$ \\
\hline The University of Tennessee (laboratory upgrades) & $\$ 250,000$ \\
\hline EcoCAR2 seed money and equipment & $\$ 350,000$ \\
\hline Total & $\mathbf{\$ 2 , 1 4 2 , 0 0 0}$ \\
\hline
\end{tabular}

\section{Support from the University}

The University of Tennessee has been a great supporter of the GATE Center. In addition to the cost sharing provisions of the Cooperative Agreement, the university has provided space for the GATE Center in the Dougherty Engineering Building. The University has also provided space and facilities for the students to conduct their research.

The University also provided support totaling approximately $\$ 200,000$ to upgrade the automotive engineering laboratories. Two additional laboratories have been established that directly support the GATE activities. 
- UTK HEV Modeling and Simulation Laboratory: a full host of computing resources are available to the students ranging from component/system/full vehicle modeling and simulation tools to computer aided design (CAD) and finite element analysis (FEA) tools

- UTK Rapid Controls Prototyping Laboratory: a diverse range of hardware platforms is available for students to development detailed hardware-in-the-loop systems where component/system/full vehicle plant models can be exercised in real-time. Students also can target supervisory control strategies (developed in the HEV Modeling and Simulation lab) to development or production level hardware. These control hardware systems can then be subjected to a range of verification tests, including fault insertion for validation of logic for maintaining safety critical systems

\section{Conclusions}

The UTK GATE Center has been an extremely valuable addition to the College of Engineering. In addition to involving fourteen GATE students (thirty six including the original GATE grant), the GATE Center has provided a focal point to bring together mechanical and electrical engineering faculty and students. The center has led to employment opportunities, opportunities for collaboration with other organizations, and has brought additional resources into the automotive systems activities at the University of Tennessee. 